\title{
Large intermixing in the InGaP/ InAlGaP laser structure using stress engineering at elevated temperature
}

Mohammed A. Majid, Ahmad A. Al-Jabr, Rami T. El Afandy, Hassan M. Oubei, Dalaver H. Anjum, et al.

Mohammed A. Majid, Ahmad A. Al-Jabr, Rami T. El Afandy, Hassan M. Oubei, Dalaver H. Anjum, Mohamed Shehata, Tien K. Ng, Boon S. Ooi, "Large intermixing in the InGaP/InAIGaP laser structure using stress engineering at elevated temperature," Proc. SPIE 10939, Novel In-Plane Semiconductor Lasers XVIII, 109390L (1 March 2019); doi: 10.1117/12.2511878 


\title{
Large intermixing in the InGaP/InAIGaP laser structure using stress engineering at elevated temperature
}

\author{
Mohammed. A. Majid ${ }^{\mathrm{a}, \mathrm{b}}$, Ahmad. A. Al-Jabr ${ }^{\mathrm{b}}$, Rami. T. ElAfandy ${ }^{\mathrm{b}}$, Hassan M. Oubei ${ }^{\mathrm{b}}$, Dalaver .H. \\ Anjum $^{\mathrm{c}}$, Mohamed. Shehata ${ }^{\mathrm{a}}$, Tien .K. Ng ${ }^{\mathrm{b}}$ and Boon. S. Ooi ${ }^{\mathrm{b}}$ \\ ${ }^{a}$ Electrical and Computer Engineering department, Effat University, Jeddah 21478, (KSA) \\ bPhotonics Laboratory, King Abdullah University of Science \& Technology (KAUST), \\ ${ }^{\mathrm{c}}$ Advanced Nanofabrication, Imaging and Characterization Core Facilities, (KAUST) \\ Thuwal 23955-6900, Kingdom of Saudi Arabia (KSA) \\ *email: boon.ooi@kaust.edu.sa; moabdulmajid@effatuniversity.edu.sa
}

\begin{abstract}
In this paper, a thermally induced dielectric strain on quantum well intermixing (QWI) technique is employed on tensilestrained InGaP/InAlGaP laser structure, to promote inter-diffusion, in conjunction with cycle annealing at elevated temperature. A bandgap blueshift as large as large as $\sim 250 \mathrm{meV}$ was observed for samples capped with a single and bilayer of the dielectric film $\left(1 \mu \mathrm{m}-\mathrm{SiO}_{2}\right.$ and $\left.0.1 \mu \mathrm{m}-\mathrm{Si}_{3} \mathrm{~N}_{4}\right)$ and annealed at a high temperature $\left(700-1000^{\circ} \mathrm{C}\right)$ for cycles of annealing steps. Samples subjected to this novel QWI technique for short duration and multiple cycle annealing steps shown a high degree of intermixing while maintaining strong photoluminescence (PL) intensity, narrow full wave at half maximum (FWHM) and good surface morphology. Laser devices fabricated using this technique, lased at a wavelength of $608 \mathrm{~nm}$ with two facet power of $\sim 46 \mathrm{~mW}$, indicating the high quality of the material. Our results show that thermal stress can be controlled by the engineering dielectric strain opening new perspectives for QWI of photonics devices.
\end{abstract}

Keywords: InGaP/InAlGaP, Visible lasers, Dielectric stress, Quantum well intermixing, Cycle annealing

\section{INTRODUCTION}

There is a strong Interest for visible light emitters for several important applications in solid-state lighting, Li-Fi, underwater visible light communication, medicine, and photodynamic therapy (PDT) ${ }^{1-3}$.Visible light emitters are nitridebased (InGaN/GaN) covering the $\sim 405-530 \mathrm{~nm}$ or phosphide-based (InGaP/InAlGaP) covering the 630-690nm wavelengths ${ }^{4-9}$. The optoelectronic devices, emitting in the green to orange spectral region $550-620 \mathrm{~nm}$ suffer from low quantum efficiency, and therefore there is a "gap" in the visible region. Large strain and Indium segregation prevent efficient laser devices beyond $540 \mathrm{~nm}$ in the III-N material system ${ }^{5}$. As for the InGaP/InAlGaP material system, Al incorporation shortens the emissions wavelength; however, efficiency is severely affected by oxygen-related defects. Also, the small band offset between the quantum well (QW) and the barrier leads to large current leakage. The lowest reported wavelength with $\mathrm{Al}$ content was $615 \mathrm{~nm}^{4}$. The bandgap of $\operatorname{In}_{x}\left(\mathrm{Al}_{\mathrm{y}} \mathrm{Ga}_{1-\mathrm{y}}\right)_{1-\mathrm{x}} \mathrm{P}$ quantum well can also be tuned by controlling the In content; however, it will lead to lattice mismatch with GaAs substrate. By applying high external

\footnotetext{
Novel In-Plane Semiconductor Lasers XVIII, edited by Alexey A. Belyanin,

Peter M. Smowton, Proc. of SPIE Vol. 10939, 109390L · C 2019 SPIE

CCC code: $0277-786 \mathrm{X} / 19 / \$ 18 \cdot$ doi: $10.1117 / 12.2511878$
} 
pressure and low temperature yellow lasing was demonstrated from red $\mathrm{InGaP} / \mathrm{InAlGaP}$ laser diodes ${ }^{10}$. However, this method is not viable for commercial applications. The other route explored by researchers, was to utilize the post-growth quantum well intermixing (QWI). Negligible wavelength shift was observed for devices capped with plasma-enhanced chemical vapor deposition (PECVD) -deposited $\mathrm{HfO}_{2}$ and $\mathrm{SiO}_{2}$ dielectric films. ${ }^{11-13}$

In this work, thermally induced dielectric strain is employed on tensile-strained InGaP/InAlGaP laser structure to promote interdiffusion via application of a single $\left(\mathrm{SiO}_{2}, \mathrm{Si}_{3} \mathrm{~N}_{4}\right)$ and bilayers $\left(\mathrm{SiO}_{2} / \mathrm{Si}_{3} \mathrm{~N}_{4}\right)$ of dielectric films at elevated temperature. A bandgap blueshift as large as large as $250-300 \mathrm{meV}$ was observed for samples capped with a single layer of $1 \mu \mathrm{m}-\mathrm{SiO} 2$ and $0.1 \mu \mathrm{m}-\mathrm{Si} 3 \mathrm{~N} 4$ and annealed at an elevated temperature for cycles of annealing steps. We discuss wavelength tuning by QWI and suppression by the engineering dielectric strain (single and bilayer), opening new perspectives for QWI of photonics devices.

\section{EXPERIMENT}

The laser structure has a single $\mathrm{QW}$ InGaP/InAlGaP sandwich between $\operatorname{In}_{0.5} \mathrm{Al}_{0.5} \mathrm{P}$ cladding layers and the GaAs contact layer and grown on GaAs substrate as shown in Figure.1. The device structure is lattice-matched to the GaAs substrate; the composition of thin $6 \mathrm{~nm} \mathrm{In}_{0.47} \mathrm{Ga}_{0.53} \mathrm{P}$ quantum well is designed to have a peak emission at $635 \pm 3 \mathrm{~nm}$ with a limited amount of strain. In our study, samples are prepared using two capping materials a $1-\mu \mathrm{m}$ thick film of $\mathrm{SiO}_{2}$ and $0.1-\mu \mathrm{m}$ Si3N4 using Plasma enhanced chemical vapor deposition (PECVD). These samples were annealed using rapid thermal processing in a nitrogen ambient at temperature values of $700^{\circ} \mathrm{C}$ to $1000^{\circ} \mathrm{C}$ in steps of $25^{\circ} \mathrm{C}$ for annealing durations between 30 s to 240 s, along with an uncapped as-grown sample. A GaAs proximity cap is used for arsenic overpressure to minimize arsenic desorption during annealing, A room-temperature PL spectroscopy apparatus equipped with a $473 \mathrm{~nm}$ cobalt laser used as the excitation source to measure the induced blueshift by the above process. Electroluminescence emissions were measured on sample blueshifted to the red-yellow region by applying front and back contacts.

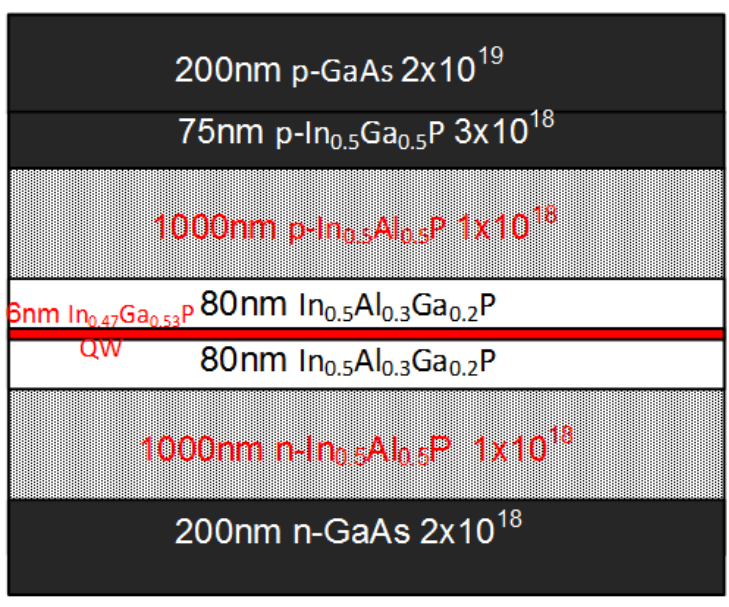

$\mathrm{N}-\mathrm{GaAs}$ Substrate

Fig. 1 The InGaP/InAlGaP laser structure with a single $\operatorname{In}_{0.47} \mathrm{Ga}_{0.53} \mathrm{P}$ quantum well. 


\section{RESULTS AND DISCUSSION}

Previously we have studied the effect of annealing temperature on group III intermixing for a $1 \mu \mathrm{m}$-SiO $\mathrm{S}_{2}$-capped sample at different temperatures from $700^{\circ} \mathrm{C}$ to $1000^{\circ} \mathrm{C}$, for $120 \mathrm{~s}$ annealing duration. We found that the annealing temperature of $925^{\circ} \mathrm{C}$ is the threshold temperature above which degree of intermixing rapidly increases ${ }^{6-9}$. A similar study is conducted for $0.1 \mu \mathrm{m}-\mathrm{Si}_{3} \mathrm{~N}_{4}$ samples for annealing temperature ranging from $700-1000^{\circ} \mathrm{C}$, for the $120 \mathrm{~s}$ duration as shown in Fig.2. Up to $900^{\circ} \mathrm{C}$, all the samples capped with $0.1 \mu \mathrm{m}-\mathrm{Si}_{3} \mathrm{~N}_{4}$ (and also $1 \mu \mathrm{m}-\mathrm{SiO}_{2}$ ) retained high photoluminescence intensity with a negligible increase in full-width at half maximum (FWHM) while maintaining good surface morphology. Above, this temperature the interface between the top contact layer of $\mathrm{InGaP} / \mathrm{InAlGaP}$ and the $\mathrm{Si}_{3} \mathrm{~N}_{4}$ starts to crack (inset Fig.2) and in some cases peeled off the top contact layers (Inset Fig 2). No intermixing observed from these samples in the temperature range $900-1000^{\circ} \mathrm{C}$ and the inevitable effect does not allow further exploration.

Interestingly, we have observed intermixing in the range of $700^{\circ} \mathrm{C}$ to $900^{\circ} \mathrm{C}$ for $\mathrm{Si}_{3} \mathrm{~N}_{4}$ capped samples with wavelength blueshift rapidly above $800^{\circ} \mathrm{C}$. The sample maintained strong PL intensity and narrow full wave at half maximum (FWHM) and preserved epitaxial quality as observed from Transmission Electron Microscopy (not shown). Some surface damage was apparent after annealing as can be seen from the optical micrograph in the inset of Fig.2, which needs to be avoided to ensure the high quality of the laser structure after the QWI process for further device fabrication.

The surface damage is detrimental to the optoelectronic devices, under a high injection current densities, defects can migrate into the active region and promote the non-radiative recombination. Understanding and solving these issues are keys to attaining high-performance devices. Based on the above analysis, $800{ }^{\circ} \mathrm{C}$, is considered as the critical temperature for enhanced intermixing in this material system for $\mathrm{Si}_{3} \mathrm{~N}_{4}$ dielectric film.

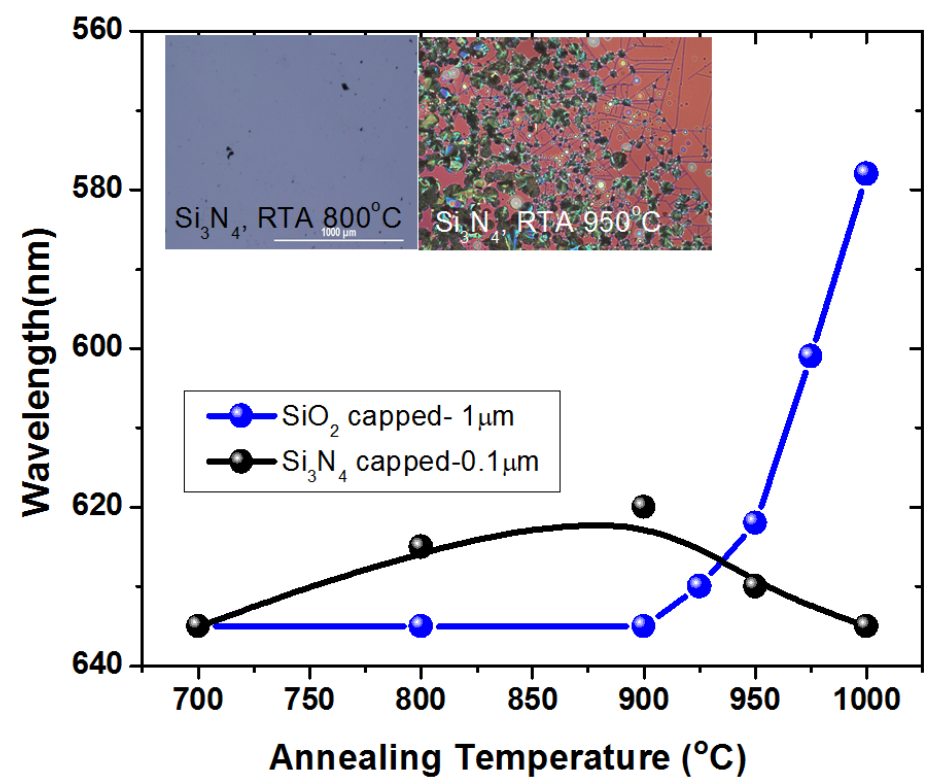

Fig. 2 The peak wavelength shift as a function of annealing temperature for $\mathrm{InGaP} / \mathrm{InAlGaP}$ with a 1- $\mu$ m thick PECVD-deposited $\mathrm{SiO}{ }_{2}$ and $0.1-\mu \mathrm{m}$ thick $\mathrm{Si}_{3} \mathrm{~N}_{4}$ capping layer annealed for $120 \mathrm{~s}$. Inset shows optical micrograph of the semiconductor surface after rapid thermal annealing (RTA) at $800^{\circ} \mathrm{C}$ and fragmented dielectric after annealing at $950^{\circ} \mathrm{C}$. 

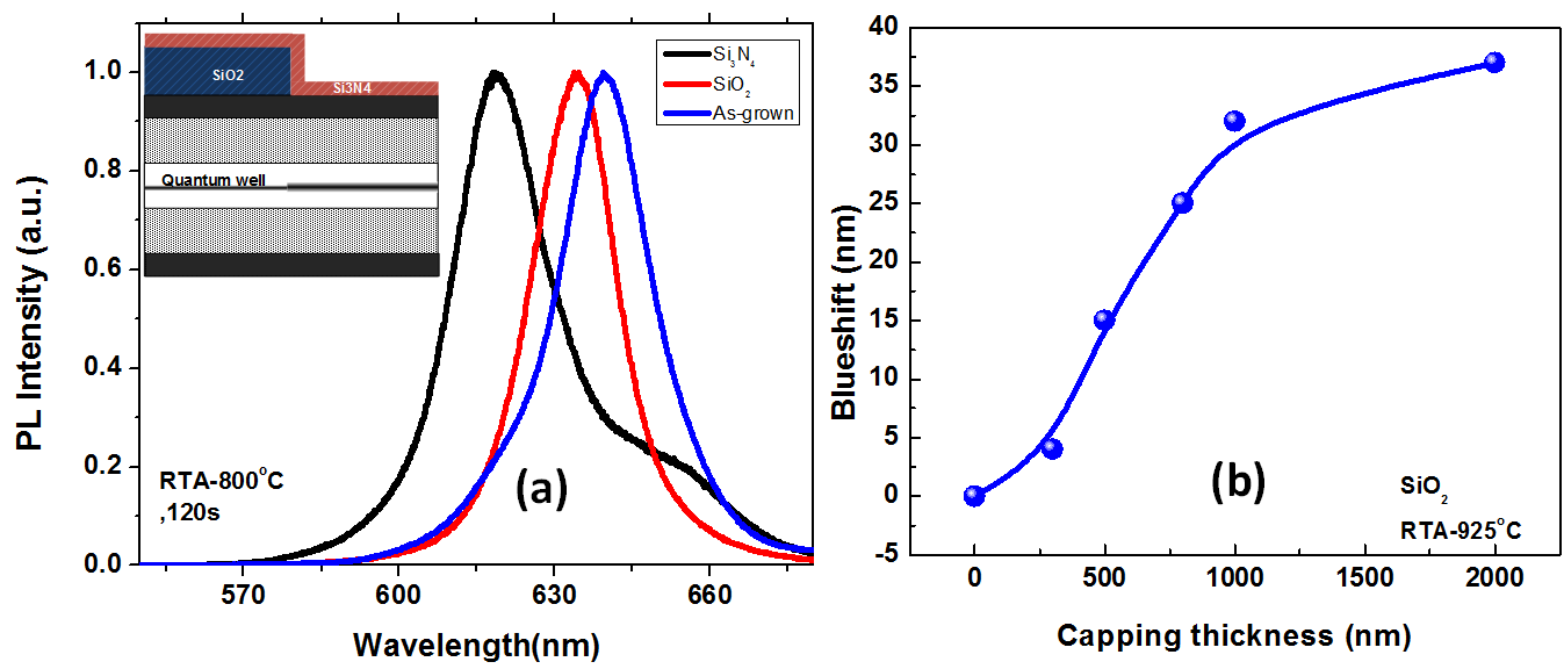

Fig. 3 (a) The peak wavelength shift for a multilayer dielectric film with a $1-\mu$ m thick $\mathrm{SiO}_{2}$ and $0.1-\mu \mathrm{m}$ thick $\mathrm{Si}_{3} \mathrm{~N}_{4}$. The inset shows the schematic of the novel quantum well intermixing $\left(\mathrm{Si}_{3} \mathrm{~N}_{4}\right)$ and suppression $\left(\mathrm{SiO}_{2}\right)$ investigated in the study. (b) the relationship between the film thickness of $\mathrm{SiO}_{2}$ and the amount of blueshift on the InGaP/InAlGaP laser structure.

Fig.3 (a) shows the peak wavelength shift for a bilayer of dielectric $1-\mu \mathrm{m}$ thick $\mathrm{SiO}_{2}$ and $0.1-\mu \mathrm{m}$ thick $\mathrm{Si}_{3} \mathrm{~N}_{4}$ annealed at $800{ }^{\circ} \mathrm{C}$ for a duration of $120 \mathrm{~s}$. The inset shows the schematic of the novel quantum well intermixing and suppression from bilayer of dielectric. Previously, we increased the strain by increasing the thickness of $\mathrm{SiO}_{2}$ capping from 2002000nm to emphasize the relationship between strain and $\mathrm{QWI}^{6-9}$. As can be seen from Fig 3(b), as the thickness increases the blueshift increase and saturates above 1000nm thickness. So it is safe to assume that the bilayer $\mathrm{SiO}_{2} / \mathrm{Si}_{3} \mathrm{~N}_{4}$, do not increase the QWI amount as shown by PL measurement in Fig. 3(a). In fact, from Fig 1, the single layer of $\mathrm{SiO}_{2}$ act like a suppressant cap for QWI below $925^{\circ} \mathrm{C}$, which is also clearly evident from the study of bilayer cap in Fig. 3(a). QWI by $\mathrm{Si}_{3} \mathrm{~N}_{4}$ and suppression by $\mathrm{SiO}_{2}$ in the single layer and bilayer of dielectrics at $800{ }^{\circ} \mathrm{C}$ offers high quantum efficiency, improved surface quality (except few defects), and good quantum well-intermixing selectivity in the InGaP/InAlGaP. These results are contrary to what is reported earlier in the case of multi-layer InGaAs/GaAs quantum well laser structure ${ }^{14-15}$.
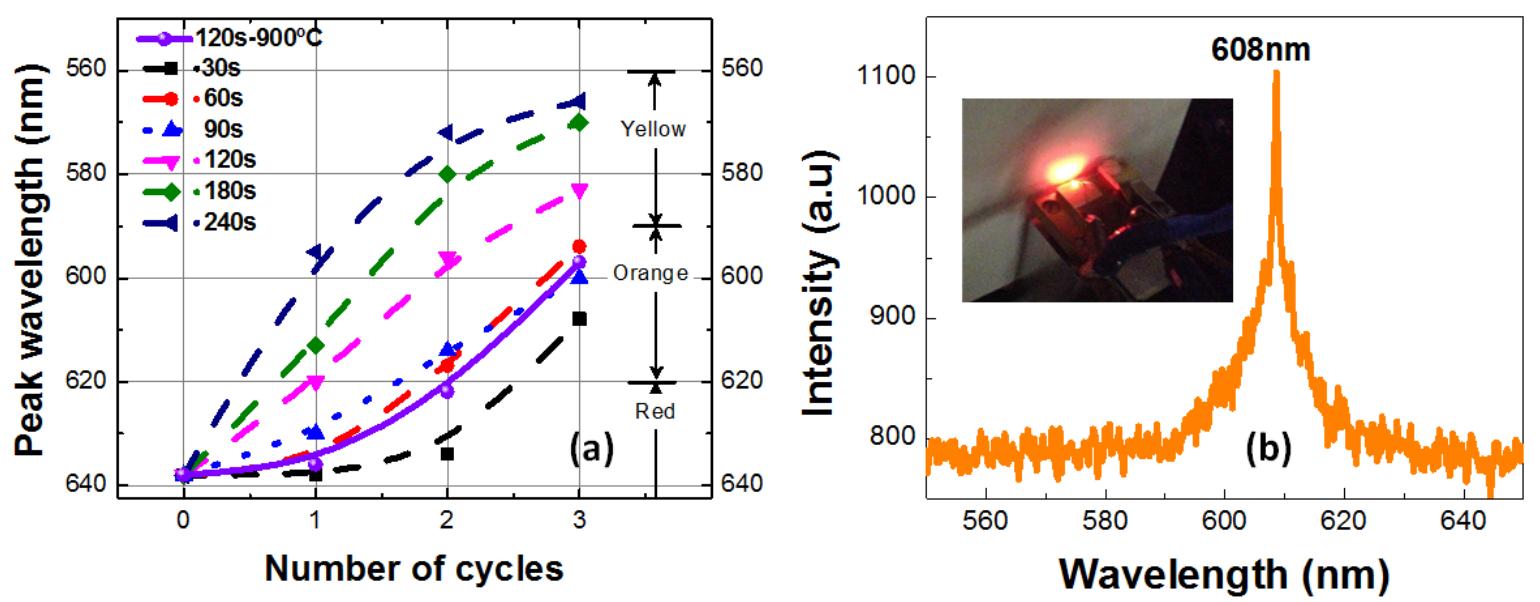

Fig. 4. (a)Room temperature photoluminescence Peaks of $\mathrm{InGaP} \backslash \mathrm{InAlGaP}$ laser samples with thick $1 \mathrm{um}-\mathrm{SiO}_{2}$ annealed at $950^{\circ} \mathrm{C}$ for 1,2 and 3 cycles for different annealing duration ${ }^{6}$. (b) Dielectric strain induced orange semiconductor laser emitting at $608 \mathrm{~nm}^{6}$. 
Previously we achieved the largest degree of QWI $(\sim 250 \mathrm{meV})$ for an annealing duration of $240 \mathrm{~s}$ at $950^{\circ} \mathrm{C}$, but the decreases in PL intensity and broadening of FWHM suggests degradation of the epitaxial quality. We noted that cycles of annealing (see Fig4 (a)) enhance the material quality for the shorter duration of annealing, in our case 30s. As a proof of material quality after intermixing, QWI was performed with the optimum parameters of $950^{\circ} \mathrm{C}$ and 30 s. The samples were annealed for 2, 5 and 9 cycles to obtain the desired wavelengths of red $(620 \mathrm{~nm})$, orange $(595 \mathrm{~nm})$ and yellow $(575$ $\mathrm{nm}$ ), respectively ${ }^{6-9}$. An efficient orange lasing around $608 \mathrm{~nm}$ demonstrated for the laser structure annealed for 5 cycles at $950^{\circ} \mathrm{C}$ for the 30 s, as shown in Fig 4(b). Fig4 (a), also shows that annealing for a longer duration (120s) and lower temperature $\left(900^{\circ} \mathrm{C}\right)$ enhance QWI for few cycles of annealing (in this case 3), presented similar PL characteristics and surface morphology as that at $950^{\circ} \mathrm{C}$ for the 30 and 60 s annealing duration.
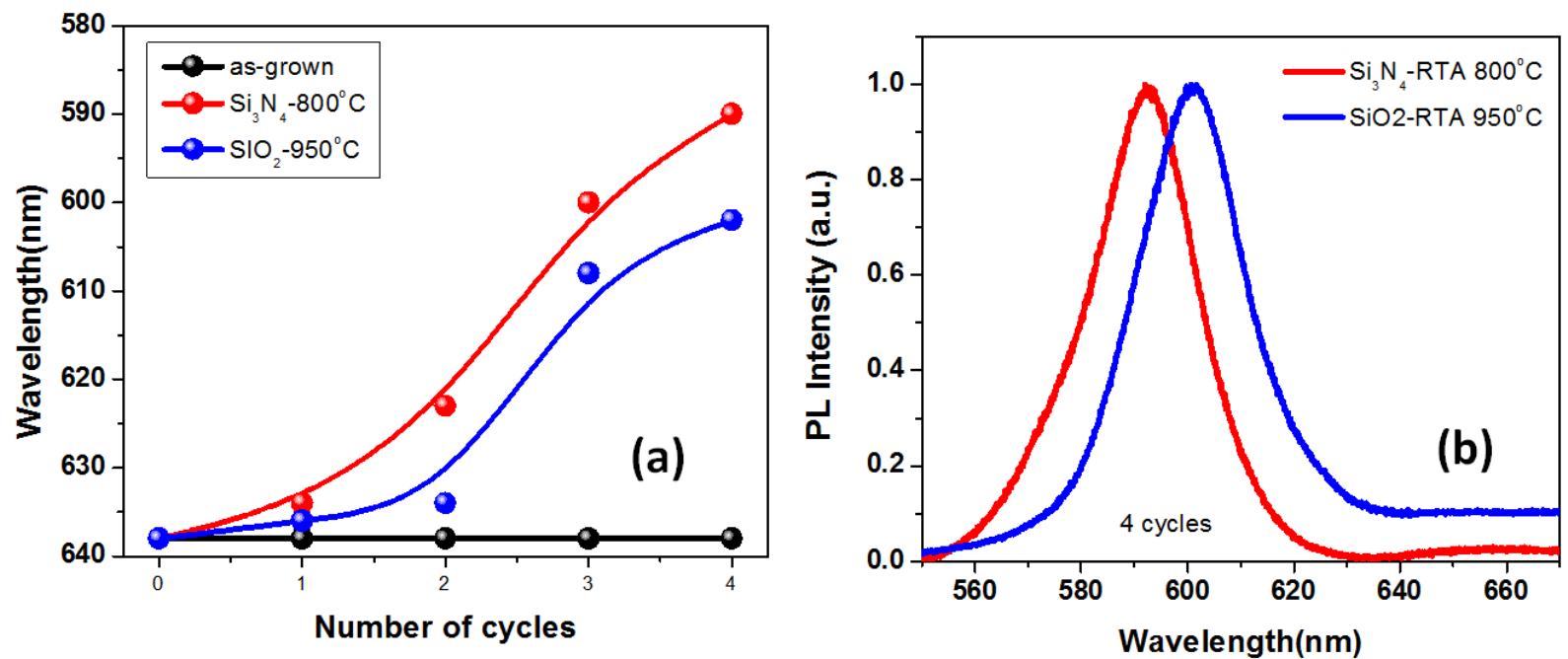

Fig.5. (a) Room-temperature PL Peaks of InGaP/InAlGaP laser samples capped with $\mathrm{Si}_{3} \mathrm{~N}_{4}$ and, $\mathrm{SiO}_{2}$ annealed at 800 and $950^{\circ} \mathrm{C}$ for $1,2,3$ and 4 cycles. (b) Peak PL emission spectra after 4 cycles of annealing.

We applied the novel QWI process for short duration of the 30s on $\mathrm{Si}_{3} \mathrm{~N}_{4}$ capped dielectric samples and compared with $\mathrm{SiO}_{2}$ capped samples of Fig.4. Samples are annealed for 1, 2, 3 and 4 cycles each of 30s duration, as shown in Fig.5 (a). We noticed no fracture of $\mathrm{Si}_{3} \mathrm{~N}_{4}$ after 4 cycles of annealing and the surface shows no visible defects after etching the dielectric. QWI was improved in the samples capped with $\mathrm{Si}_{3} \mathrm{~N}_{4}$ as compared to $\mathrm{SiO}_{2}$ dielectric film, this is evident by the bandgap blueshift from red $(\sim 640 \mathrm{~nm})$ to yellow $(\sim 590)$ for $\mathrm{Si}_{3} \mathrm{~N}_{4}$ and red $(\sim 640 \mathrm{~nm})$ to orange $(\sim 600)$ for $\mathrm{SiO}_{2}$ capped samples as shown in Fig. 5 (b). Considering cumulative annealing time of 120s (4 cycles of 30sec) and one cycle of 120 s, the short duration and multiple cycles of annealing is the key to enhance the QWI. In our case, we noticed an increased blueshift $\sim 25 \mathrm{~nm}$ for 4 cycles of the $30 \mathrm{~s}$, as compared to one cycle of 120 s for the $\mathrm{Si}_{3} \mathrm{~N}_{4}$ capped dielectric film at $800{ }^{\circ} \mathrm{C}$. Using this method wavelength tunability from $\sim 640 \mathrm{~nm}$ to $\sim 555 \mathrm{~nm}(\sim 300 \mathrm{meV})$ is demonstrated for both the capping samples for multiple ( 14-17) cycles of annealing of short duration. Details of this characterization will be reported elsewhere. 


\section{CONCLUSION}

We presented a thermally induced dielectric strain on quantum well intermixing (QWI) technique on a tensile-strained InAlGaP/InGaP red laser structure that induces the large degree of bandgap blueshift. A maximum bandgap shift of 250-300 meV with an original wavelength of $640 \mathrm{~nm}$ is observed in this material system with a single and bilayer of the dielectric film for short duration and multiple cycles of annealing. The fabricated QWI samples were characterized for electroluminescence and photoluminescence which indicated high-quality of the material.

\section{ACKNOWLEDGEMENTS}

The authors gratefully acknowledge the financial support from KACST Technology Innovation Center for Solid State Lighting at KAUST and Research Consultancy Institute (RCI) at Effat University.

\section{REFERENCES}

[1] Tsao, J. Y. , Crawford, M. H., Coltrin, M. E., Fischer, A. J., Koleske, D. D., G. S. Subramania, et al., "Solid-State Lighting: Toward Smart and Ultra-efficient Solid-State Lighting (Advanced Optical Materials 9/2014)," Advanced Optical Materials, vol. 2, pp. 803-803, (2014).

[2] Conte, C. , Ungaro, F., Mazzaglia, A., and Quaglia, F., "Photodynamic Therapy for Cancer: Principles, Clinical Applications, and Nanotechnological Approaches," in Nano-Oncologicals, ed: Springer, pp. 123-160, (2014).

[3] Janjua, B., Oubei, H.M., Retamal, J. R. D., Ng, T. K., Tsai, C.T., Wang, H.Y., et al., "Going beyond 4 Gbps data rate by employing RGB laser diodes for visible light communication," Optics express, 23, 18746-18753 (2015).

[4] Tanaka, T., Yanagisawa, H., Takimoto, M., and Minagawa, S., "Tensile-strained AlGaInP single quantum-well LDs emitting at $615 \mathrm{~nm}$," Electronics Letters, vol. 29, pp. 1864-1866, 1993.

[5] Nakamura, S., Senoh, M., Iwasa, N., and Nagahama, S.I., "High-brightness InGaN blue, green and yellow lightemitting diodes with quantum well structures," Japanese Journal of Applied Physics, part 2 letters, 34, 797 (1995).

[6] M. A. Majid, A. A. Al-Jabr, R. T. Elafandy, H. M. Oubei, M. S. Alias, B. A. Alnahhas, D. H. Anjum, T. K. Ng, M. Shehata, and B. S. Ooi, "First demonstration of orange-yellow light emitter devices in InGaP/InAlGaP laser structure using strain-induced quantum well intermixing technique," Proc. SPIE 9767, 97670A (2016)

[7] A. A. Al-Jabr, M. A. Majid, M. S. Alias, D. H. Anjum, T. K. Ng, and B. S. Ooi, "Large bandgap blueshifts in the InGaP/InAlGaP laser structure using novel strain-induced quantum well intermixing," Journal of Applied Physics, vol. 119, p. 135703, (2016).

[8] Majid, M.A., Al-Jabr, A.A., Oubei, H.M., Alias, M.S., Anjum, D.H., Ng, T.K. and Ooi, B.S., "First demonstration of InGaP/InAlGaP based orange laser emitting at $608 \mathrm{~nm}$," Electronics Letters, 51(14), 1102$1104(2015)$

[9] A. A. Al-Jabr, M. A. Majid, C. Shen, T. K. Ng and B. S. Ooi " Red to green emitters from InGaP/InAlGaP laser structure by strain-induced quantum-well intermixing ", Proc. SPIE 9892, Semiconductor Lasers and Laser Dynamics VII, 98921B (2016)

[10] Bohdan, R., Bercha, A., Trzeciakowski, W., Dybała, F., Piechal, B., Sanayeh, M.B., Reufer, M., Brick, P.: "Yellow AlGaInP/InGaP laser diodes achieved by pressure and temperature tuning," Journal of Applied Physics, 104 (6), 063105-063105-5 (2008). 
[11] Ooi, B. S., McIvlaney, K., Street, M. W., Saher Helmy, A., Ayling, S. G., Bryce, A. C., and J. H. Marsh, "Selective quantum well intermixing in GaAs/AlGaAs structures using impurity free vacancy diffusion", IEEE J. Quantum Electron, 33, 1784 -1793 (1997).

[12] Hala, H. A., Khan, M.Z.M, Majid M.A., Ng T.K, Ooi. B.S, "InAs/GaAs quantum-dot intermixing: comparison of various dielectric encapsulants," Opt. Eng. 54(10) 107107 (2015)

[13] Alhashim, H. H. , Khan, M. Z. M., Majid, M. A., Ng, T. K., and Ooi, B. S., "Sub-1100 nm lasing from postgrowth intermixed InAs/GaAs quantum-dot lasers," in Electronics Letters, vol. 51, no. 18, pp. 1444-1445, 39

[14] Yu J. S, Song J. D, Lee Y .T and Lim .H, "Fabrication of multi-wavelength In0.2Ga0.8As/GaAs multiple quantum well laser diodes by area-selective impurity-free vacancy disordering using $\mathrm{SiOx}$ capping layers with different stoichiometries" Appl. Phys. A $80: 847$, (2005)

[15] Arslan, S. , Demir, A., Şahin, S., and Aydınlı, A. "Conservation of quantum efficiency in quantum well intermixing by stress engineering with dielectric bilayers", Semicond. Sci. Technol., vol. 33, no. 2, pp. 025001, (2018). 